\title{
Prevalence and genotypes of Rotavirus among children under 5 years presenting with diarrhoea in Moshi, Tanzania: a hospital based cross sectional study
}

\author{
Deborah N. Mchaile ${ }^{1,2^{*}}$, Rune N. Philemon ${ }^{1,2}$, Sonia Kabika², Evelyn Albogast ${ }^{2}$, Kikoti J. Morijo $^{2}$, \\ Emmanuel Kifaro ${ }^{3}$ and Blandina T. Mmbaga ${ }^{1,2,4}$
}

\begin{abstract}
Background: Diarrhoea is a main cause of morbidity and mortality in children under 5 responsible for approximately four billion cases and 1.1 million deaths annually. In developing countries, it causes two million deaths each year. The major causative organism responsible is Rotavirus which is responsible for one-third of hospitalizations with approximately $40 \%$ mortality.

Results: The prevalence of Rotavirus infection was $26.4 \%$ (73/277). The predominant strain of Rotavirus found was $\mathrm{G} 1$ 21/73 (53.8\%), followed by G8 9/73 (23.1\%), G12 5/73 (12.8\%), G9 3/73(7.7\%) and G4 1/73 (2.6\%). All serotypes identified were in children who had completed Rotavirus vaccination except for one who had $\mathrm{G} 8$ in whom the vaccine was introduced after they had completed immunizations.

Conclusion: The overall prevalence of rotavirus has reduced from 33.2\% in 2009 to $26.4 \%$ in 2016 . We have found G1 to be the predominant serotype as well as other circulating serotypes namely G4, G8, G9 and G12. Despite a reduction in prevalence, there is a need for further rotavirus surveillance in the region.
\end{abstract}

Keywords: Rotavirus, Diarrhoea, Under five, Moshi Municipality

\section{Background}

Diarrhoea is a main cause of morbidity and mortality in children under 5 responsible for approximately four billion cases and 1.1 million deaths annually [1]. In developing countries, it causes two million deaths each year [2]. The major causative organism responsible is Rotavirus which is responsible for one-third of hospitalizations with approximately $40 \%$ mortality [3].

Rotavirus mainly affects children, with young children below five years being the most vulnerable. The prevalence of rotavirus is highest among children from 13 to

\footnotetext{
*Correspondence: deborahsia@hotmail.co.uk

1 Department of Pediatrics and Child Health, Kilimanjaro Christian Medical Centre, Moshi, Tanzania

Full list of author information is available at the end of the article
}

24 months $(57.6 \%)$ followed by those less than 1 year (46.3\%) and lowest among children aged 1 to 5 years [4].

Rotavirus is an RNA virus and a member of the Reoviridae family [5]. It has groups ranging from $A$ to $G$ with Group A having multiple strains and causing majority of childhood infections [6]. The Rotavirus has 14G and 11P serotypes which are critical to vaccine developments; the serotypes are the vaccine targets for stimulating a protective immune response [7]. G1P[8] is the commonest circulating serotype accounting for two-thirds of infection [8].Strain diversity has been reported and is greatest in Africa and Asia due to mixed infections and proximity to domestic animals shedding the virus [8]. There are also changes in genotypes circulating due to seasonal variation [9]. In Africa the most prevalent strains were G1P [8] and G3P $[8,10]$. 
Rotavirus vaccine (Rotarix) was introduced into the Tanzania Expanded Programme of Immunization in January 2013. Studies have shown vaccine effectiveness to be $98 \%$ in high income countries as compared to $59 \%$ in middle income countries [11]. In Malawi data showed the vaccine to be $64 \%$ effective in rotavirus negative individuals [12]. In the pre-rotavirus vaccine era, rotavirus diarrhoea resulted in 220,000 annual hospital admissions, 1.8 million healthcare visits and 7.1 million episodes of diarrhoea among children living in developed countries [13]. In the United States, there were an estimated 20-60 deaths, 55,000 to 75,000 hospitalizations and 410,000 outpatient visits annually [14]. In the post vaccination era, it is estimated that approximately $36 \%$ of diarrhoea hospitalizations in children less than 5 years in countries where rotavirus surveillance is being carried out, can be attributed to rotavirus infection [3].

Prior to introduction of vaccine in Tanzania, the prevalence of Rotavirus in Dar-es-Salaam was 32.5\% [15]. Previous studies have reported the emergence of new strains such as G9 and others like G12, G4 and G8 in Dar-esSalaam [15]. Despite this there have not been any published studies to date looking at the circulating serotypes in the Kilimanjaro region both in the pre-or post-vaccine era. Because of this we fail to understand if the diarrhoea cases being observed are due to different virus strains or the same strain targeted by vaccine. We also fail to comment on the circulating serotypes. This study aimed to determine the prevalence of Rotavirus among children under 5 in Moshi, Tanzania post vaccination and the circulating serotypes in the region. Kilimanjaro Region is one of Tanzania's 31 administrative regions. It has 7 districts with the regional capital being Moshi municipality. Moshi is situated on the lower slopes of Mount Kilimanjaro and covers about $59^{2} \mathrm{~km}\left(23^{2} \mathrm{~m}\right)$ with a population of 184,292 per the 2012 census.

\section{Methods}

\section{Study design and setting}

This was a hospital based cross sectional study involving children under 5 years of age in Moshi Municipality presenting with diarrhoea from January 2016 to May 2016.

Four health facilities were purposively selected to cover multiple tiers of health care and these included: St Joseph Hospital, Kilimanjaro Christian Medical Centre (KCMC) Hospital, Majengo and Pasua Health Centre. KCMC is one of the zonal referral hospitals in Tanzania; it serves as a referral, research and teaching hospital, located in the Northeastern part of Tanzania. It serves five regions in the Northern part of Tanzania, namely, Kilimanjaro, Tanga, Arusha, Manyara and Singida with an estimated population over $15,000,000$ people. It has a bed capacity of 450 beds. St Joseph is a designated District Hospital which has several departments and admits approximately 1787 pediatric patients annually. Majengo Health Centre and Pasua Health Centre are secondary level health centres. Both serve an average of 4920 patients per year, (out-patient department), 564 in patients annually at Pasua Health Centre and 5491 outpatients annually at Majengo Health Centre.

\section{Study population}

All children aged 2-59 months presenting with passage of 3 or more motions of loose or watery stools per $24 \mathrm{~h}$ receiving care in the four study centres during the study period were included. Sample size was estimated per hospital attendances. At least 17 patients were expected from each of the 4 study sites each month. Data was collected for 5 months. The expected sample size was 340 .

\section{Inclusion and exclusion criteria}

We included all children presenting with diarrhoea aged 2-59 months and excluded those children whose parents/guardian did not agree nor sign the consent form.

\section{Data collection and study variables}

A questionnaire was used to collect socio-demographic and clinical data from participants with the aid of research assistants. Our outcome variable was rotavirus and predictor variables were age, sex, duration of diarrhoea, frequency of diarrhoea, completion of rotavirus vaccine and degree of dehydration.

The fecal specimens were collected by research assistants and transported to the department of clinical laboratory, molecular biology unit and stored at $-20{ }^{\circ} \mathrm{C}$ until used for the detection of group A rotavirus.

\section{Rotavirus Antigen Detection}

The specimens were tested by a solid-phase sandwich type enzyme immunoassay method according to manufacturer instructions Rotavirus Antigen ELISA, Epitope diagnostic Inc (Carroll Road San Diego, USA), Catalogue No: KT 841. The optic density (OD) values above the cut off point $1.1 \mathrm{x}$ (mean absorbance of negative control +0.08$)$ were considered positive for rotavirus antigen.

\section{Molecular typing of rotavirus Viral RNA extraction}

$1 \mathrm{ml}$ of $10 \%(\mathrm{w} / \mathrm{v})$ fecal suspension in phosphate-buffered saline (PBS) was prepared by thorough mixed using vortex and clarified by centrifugation for $5 \mathrm{~min}$ at room temperature and $10,000 \mathrm{rpm}$. The clarified supernatant was collected for viral genome extraction. Double-stranded RNA was extracted according to the manufacturer's instructions from $140 \mu \mathrm{Ls}$ of collected 
supernatant using the QIAamp Viral RNA Mini Kit (Qiagen/Westburg, Leusden, Netherlands), Catalogue Number: 52906.

\section{Reverse Transcription and G-typing of Rotaviruses}

About $40 \mu \mathrm{l}$ of extracted nucleic acid were transferred to a PCR tube. The dsRNA was denatured at $97{ }^{\circ} \mathrm{C}$ for $5 \mathrm{~min}$, and then chilled on ice for $2 \mathrm{~min}$. The 10X buffer II (Invitrogen) $7.0 \mu \mathrm{l}, 50 \mathrm{mM} \mathrm{MgCl} 27.0 \mu \mathrm{l}$, Random primers $1.0 \mu \mathrm{l}, \mathrm{dNTPs}(10 \mathrm{mM}) 2.0 \mu \mathrm{l}, \mathrm{M}-\mathrm{MLV}(200 \mathrm{U} / \mu \mathrm{l})$ Invitrogen $2.0 \mu \mathrm{l}$, RNase-free $\mathrm{H} 2 \mathrm{O} 11.0 \mu \mathrm{l}$, to make total volume of $30.0 \mu \mathrm{l}$. Then $30 \mu \mathrm{l}$ of RT mix was added to each tube containing the extracted RNA. Incubated at $42{ }^{\circ} \mathrm{C}$ for $50 \mathrm{~min}$, and then was incubate again at $95^{\circ} \mathrm{C}$ for $5 \mathrm{~min}$ followed by chilling on ice for $2 \mathrm{~min}$. The total volume was $70 \mu \mathrm{l}$ of cDNA was obtained and stored at $-20{ }^{\circ} \mathrm{C}$ ready for $\mathrm{PCR}$.

\section{G-typing consensus PCR (VP7)}

The first-round PCR mix was prepared with $10 \mathrm{X}$ buffer II (Invitrogen) $4.5 \mu \mathrm{l}, 50 \mathrm{mM} \mathrm{MgCl} 2.0 \mu \mathrm{l}$, dNTPs $(10 \mathrm{mM})$ $1.0 \mu \mathrm{l}$, Taq polymerase $(5 \mathrm{U} / \mu \mathrm{l})$ (Invitrogen) $0.2 \mu \mathrm{l}$, Primer VP7-F $(20 \mathrm{pmol} / \mu \mathrm{l}) 1.0 \mu \mathrm{l}$, Primer VP7-R $(20 \mathrm{pmol} / \mu \mathrm{l})$ $1.0 \mu \mathrm{l}$, RNase-free $\mathrm{H} 2 \mathrm{O} 35.3 \mu \mathrm{l}$, to make total volume $45.0 \mu \mathrm{l} .45 \mu \mathrm{l}$ of PCR mix was added to each PCR tube, and $5 \mu \mathrm{l}$ of cDNA (from the RT reaction) was added, and tubes transferred to thermal cycler and cycle conditions as provided. The samples were then separated in $2 \%$ agarose gel electrophoresis to see positive samples.

The second-round PCR mix was then prepared with 10X buffer II $4.8 \mu \mathrm{l}, 50 \mathrm{mM} \mathrm{MgCl} 22.5 \mathrm{ul}$, dNTPs $(10 \mathrm{mM}) 1.0 \mathrm{ul}$, Taq polymerase $(5 \mathrm{U} / \mu \mathrm{l}) 0.2 \mathrm{ul}$, Primer VP7-R $(20 \mathrm{pmol} / \mu \mathrm{l}) 1.0 \mu \mathrm{l}$, and $1.0 \mu \mathrm{l}(20 \mathrm{pmol} / \mu \mathrm{l})$ of each strain specific primers $\mathrm{G} 1$ to $\mathrm{G} 12$, RNase-free $\mathrm{H}_{2} \mathrm{O}$ $30.5 \mu \mathrm{l}$ to make total volume of $48.0 \mu \mathrm{l} .48 \mu \mathrm{l}$ of secondround mix was then added to each PCR tube and then $2 \mu \mathrm{l}$ of first round product was added, and PCR was run under the following temperature cycles conditions.

\section{Data analysis}

Data was analysed using SPSS version 22. Descriptive summaries were prepared. Categorical and Numerical data were summarised using their respective measures of central tendency and measures of spread and presented using tables.

\section{Results}

In total, 277 children under 5 years of age presenting with diarrhoea from our four study sites were enrolled during the study period. We failed to meet the estimated sample size due to low turnout of patients during the study period. Of these 16 were from Majengo Health Centre,70 from KCMC Hospital,117 from St Joseph District
Hospital and 74 from Pasua Health Centre respectively. The median age was 11 (IQR 56) months with more than half being females 143/277 (51.6\%). The majority reported to be living in Moshi urban 239/277 (86.3\%) and reported tap water as their main source of water $257 / 277$ (92.8\%); only $84 / 277$ (30.3\%) caregivers reported to boil drinking water (Table 1 ).

The overall prevalence of Rotavirus in our study was $26.4 \%$ (73/277); 29/73 (39.7\%) in children aged less than 12 months, $34.2 \%$ (25/73) in children aged 13-24 months and $21.9 \%(16 / 73)$ among children older than 24 months.

Of those with Rotavirus positive by ELISA, 41/73 (56\%) had PCR done for G-typing consensus PCR (VP7) using strain specific primers. PCR was performed on 41 samples out of 73 due to reagent stock out. The most common serotypes were G1 21/39 (53.8\%) followed by G8 9/39 (23.1\%) and G12 5/39 (12.8\%), (Table 2). Only one child with G8 serotypes had not received Rotavirus

Table 1 Social-demographic characteristics of participants ( $\mathrm{n}=\mathbf{2 7 7}$ )

\begin{tabular}{|c|c|c|}
\hline Characteristic & No & $\%$ \\
\hline \multicolumn{3}{|c|}{ Age (months) $(n=270)^{*}$} \\
\hline$<12$ & 155 & 57.4 \\
\hline $13-24$ & 75 & 27.8 \\
\hline$>24$ & 40 & 14.8 \\
\hline Median (IQR) & $11(56)$ & \\
\hline \multicolumn{3}{|l|}{ Sex } \\
\hline Male & 134 & 48.4 \\
\hline Female & 143 & 51.6 \\
\hline \multicolumn{3}{|l|}{ Residence } \\
\hline Moshi urban & 239 & 86.3 \\
\hline Moshi rural & 22 & 7.9 \\
\hline Mwanga & 5 & 1.8 \\
\hline Others & 11 & 3.9 \\
\hline \multicolumn{3}{|l|}{ Water source } \\
\hline River & 5 & 1.8 \\
\hline Tap & 257 & 92.8 \\
\hline Well & 15 & 5.4 \\
\hline \multicolumn{3}{|c|}{ Drink boiled water } \\
\hline Yes & 84 & 30.3 \\
\hline No & 193 & 69.7 \\
\hline \multicolumn{3}{|c|}{ Type of toilet used } \\
\hline Bush & 2 & 0.7 \\
\hline Flush toilet & 159 & 57.4 \\
\hline Pit latrine & 116 & 41.9 \\
\hline \multicolumn{3}{|c|}{ Rotavirus vaccine completed } \\
\hline Yes & 259 & 93.5 \\
\hline $\mathrm{No}^{* *}$ & 18 & 6.5 \\
\hline
\end{tabular}

We collected data from 277 children under 5 years of age presenting with diarrhoea

* Of these 3 did not specify a date of birth hence we had only 273 children in the age category

** 6 of the children had not been vaccinated as the vaccine was introduced after their time 
Table 2 G serotypes in patients with Rotavirus $(n=41)$

\begin{tabular}{lrrl}
\hline Genotype & $\mathbf{n}^{*}$ & $\%$ & Completed rotavirus vaccine \\
\hline G1 & 21 & 53.8 & $21 / 21$ \\
G4 & 1 & 2.6 & $1 / 1$ \\
G8 & 9 & 23.1 & $8 / 9$ \\
G9 & 3 & 7.7 & $3 / 3$ \\
G12 & 5 & 12.8 & $5 / 5$
\end{tabular}

$\mathrm{G}$ genotyping in children who were positive for Rotavirus by ELISA

*We did genotyping on 41 samples, though two failed testing hence only 39 were included in the final analysis

vaccination since the vaccine had not been introduced in the Tanzanian EPI schedule during the time he was young, all others with $\mathrm{G}$ serotype identified had received the vaccine.

\section{Discussion}

This study focused on determining the prevalence and genotypes of Rotavirus among children under five presenting with diarrhoea in four hospitals/health centres in Moshi Municipality in Northern Tanzania. We found the prevalence of Rotavirus to be $26.4 \%$ with children less than 24 months of age being most affected. The genotypes seen in children who had Rotavirus were G1, G4, G8, G9 and G12. Those who had completed Rotavirus vaccine had G1 serotype but also displayed the other strains.

In comparison to other studies done around the world; our findings were similar to studies done in Mali by Ouermi et al. [16] and in Tanzania, Mwanza by Temu et al. [17] which found prevalence's of 22.7 and $20.7 \%$, respectively. This similarity could be attributed to the fact that they had the same study duration and both were carried out in hospital settings. The former studies were both pre-vaccine studies which were carried out in Africa. The low prevalence in Mali could be due to their small sample size. Similarities were also seen in developed countries, in Japan a study done by Phan et al. [18] found a prevalence of $14.9 \%$.

Differences were observed in Yemen in 2014 in a study done by Badani et al. [19] with a prevalence of $45.9 \%$ and in 2010 Nakawesi et al. [20] in Uganda found a prevalence of $45.4 \%$. Both studies were hospital based and done before the Rotavirus vaccine was introduced in their respective regions. Gachanja et al. [21] in 2016 in Arusha, Tanzania reported a prevalence of $37 \%$ which is higher compare to the observed from our study. This study was done after introduction of Rotavirus vaccine as our study, however, the higher prevalence reported could be attributed by the fact that Arusha is a mainly pastoral community and living near livestock is a risk factor for acquiring Rotavirus as there are also bovine strains which can affect humans.

In our study we found the genotypes in 41 of the children who had Rotavirus were G1, G4, G8, G9 and G12. We also found genotype G1, G4, G9 and G12 was in all the children who had completed Rotavirus vaccine, except G8 where one child was not vaccinated. Our findings were similar to those by Kiulia et al. [22], 2008 in Kenya who found G1, G8 and G9 to be the circulating strains. This similarity could be attributed to both studies being done in the same geographical setting and same study population despite the former study being a prevaccine study. Both Moyo et al. [15] in Tanzania in (2014) and Ansari et al. [23] in Nepal in (2013) found genotypes similar to ours. This similarity could be attributed to the fact that the study included all children under 5 like ours and are known to be high risk group for acquiring Rotavirus as well as having used similar detection methods. Moyo et al. [15] in Tanzania was the first to describe prevaccine serotypes. Our study is of value as it's the first to be done in the region. We cannot comment if the prevalence of these strains has increased or not since this is the first study to be done looking at the strain patterns in Kilimanjaro region. We now have baseline information to monitor trend and pattern these other subtypes.

Differences were noted in studies by Badani et al. [19] from Yemen in 2014, Sanchez-Uribe et al. [24], 2014 from Mexico who found G2P [4] and G9P [4]. This difference is due to the fact that both studies were able to do $\mathrm{P}$ genotyping unlike our study hence were able to report combination genotypes that existed in their respective region. Both $G$ and $P$ typing are critical for vaccine development [6]. Li et al. [25], 2014 in China found G1, G2, G3 and G9 and in which some strains were different from our study. This difference could be attributed to the fact that his study was done in the pre-vaccine era and hence no baseline serotypes were known making comparability difficult. Moyo et al. in 2007 [26] in Tanzania reported G1, G3 and G9 to be the serotypes presented with G1 being dominated which is similar to this study; however I did not find G3 in this study. This difference could be due to the fact it was a pre-vaccine study and done only in one season hence no room for changing of serotypes due to selection pressure exerted by vaccine or the seasonal effect of Rotavirus. However, looking at Moyo et al. study and our study as both done in Tanzania, we can say that majority of pre-and post vaccine strains are still dominating in Tanzania.

\section{Strengths and weaknesses}

This is the first post vaccine study to be done in the Kilimanjaro region. It covered multiple tiers of health care and it's the first to report genotypes in the Kilimanjaro 
region. We failed to meet the required sample size due to low turnout of patients during the study period and due to short duration of study also could not comment on seasonality of Rotavirus. We were not able to perform P-typing of Rotavirus in our study and were also not able to do DNA sequencing to check for similarities between the vaccine strain and the G1 we found. This was also a hospital based study so we may have missed a lot of nonhospitalised cases.

\section{Conclusion}

Rotavirus is responsible for severe gastroenteritis in children under 5 years with a prevalence of $26.4 \%$ post vaccine era in Moshi, Tanzania. Most affected age group being children under 24 months of age. The dominated genotype was G1 53.8\% with all children with this strain being received vaccine. Strain diversity was noted mostly in children who had completed rotavirus vaccine.

There is a need for continuous surveillance by relevant authorities of circulating serotypes as well further studies on vaccine efficacy. Long term assessment of vaccine potency, efficacy and circulating strain is needed so as to inform on the need for new vaccine or introduction of other genotype vaccines in the vaccination program.

\section{Additional file}

Additional file 1. The questionnaire used for data collection from parents of children under 5 years of age presenting with diarrhoea in Moshi, Tanzania.

\section{Abbreviations}

DNA: deoxyribonucleic acid; KCMC: Kilimanjaro Christian Medical Centre; PCR: Polymerase chain reaction; RNA: ribonucleic acid; SPSS: Statistical Package for the Social Sciences.

\section{Authors' contributions}

DNM, RNP and BTM designed the study; DNM, RNP, BTM and EK inputs in the study design and conduct; DNM, EA, KM, SK data collection; DNM, EA, KM and SK input in the analysis; EK carried out the ELISA tests and PCR testing. All authors read and approved the final manuscript.

\section{Author details \\ 1 Department of Pediatrics and Child Health, Kilimanjaro Christian Medical Centre, Moshi, Tanzania. ${ }^{2}$ Kilimanjaro Christian Medical University College, Moshi, Tanzania. ${ }^{3}$ Department of Veterinary Microbiology and Parasitology, Sokoine University of Agriculture (SUA), Morogoro, Tanzania. ${ }^{4}$ Kilimanjaro Clinical Research Institute, Moshi, Tanzania.}

\section{Acknowledgements}

The authors would like to acknowledge the support received from the Mentored Research Training Program (MRTP) from the Kilimanjaro Christian Medical University College with HRSA Award T84HA21123. To the study participants for their readiness to provide data which made this work possible. To Gaston Kagaruki who helped in running of the ELISA tests. To Dr. Sia E. Msuya, Nerey Mchaile and Wilfred Kabondo for their support during the study activities.

\section{Competing interests}

The authors declare that they have no competing interests.

\section{Availability of data and materials}

All data and materials pertaining to this study can be made available on request. The questionnaires for each of the study participants are currently in the Institute of Public Health, Kilimanjaro Christian Medical University College.

\section{Consent to publish}

Parents of all study participants signed a written informed consent explaining the aim of the study and that results will be made available for publication.

\section{Ethics and consent to participate}

Approval to conduct the study was obtained from KCMUCo Research and Ethics Committee. Permission to conduct the study was also obtained from the Executive Director of KCMC Hospital and the Head of Department of Pediatrics, District Medical Officer and from Medical Doctor in charge at St. Joseph Hospital, Pasua and Majengo Health Centre respectively. Formal consent both verbally and written was obtained from the parents of the study participants.

\section{Funding support}

This project was supported by Mentored Research Training Program (MRTP) from the Kilimanjaro Christian Medical University College with HRSA Award T84HA21123.

\section{Publisher's Note}

Springer Nature remains neutral with regard to jurisdictional claims in published maps and institutional affiliations.

Received: 9 January 2017 Accepted: 27 October 2017

Published online: 30 October 2017

\section{References}

1. Global Denno D, Health Child. Global Child Health. Pediatrics Rev. 2011;32(2):e25-38.

2. Villar DG, De Sautu BG, Granados A. Acute Gastroenteritis. Pediatrics in Review. 2012;33:487-96.

3. Centers for Disease Control and Prevention. Rotavirus surveillanceworldwide, 2009. MMWR Morb Mortal Wkly Rep. 2011;60:514-6.

4. Nguyen TV, Le Van P, Le Huy C, Weintraub A. Diarrhoea caused by Rotavirus in children less than 5 years of age in Hanoi, Vietnam. J Clin Microbiol. 2004:42:5745-50.

5. Chen SC, Lia-Beng Huang TLM, Chen Kow-Tong. Rotavirus infection and the current status of rotavirus vaccines. J Formosan Med Assoc. 2012;111:183-93.

6. Cox E, Christenson JC. Rotavirus. Pediatr Rev. 2012;33(10):439-47.

7. Dennehy P. Rotavirus infection, an update on management and prevention. Adv Paediatr. 2012;10:47-74.

8. Sharma S, Paul VK, Bhan MK, Ray P. Genomic characterization of nontypeable rotaviruses and detection of a rare G8 strain in Delhi, India. J Clin Microbiol. 2009:47(12):3998.

9. Grimwood K, Lambert SB, Milne RJ. Rotavirus infections and vaccines: burden of illness and potential impact of vaccination. Pediatric Drugs. 2010;12(4):235-56.

10. Cunliffe NA, Bresee JS, Gentsch JR, Glass RI, Hart CA. The expanding diversity of rotaviruses. Lancet. 2002;359(9307):640-2.

11. Leshem E, Lopman B, Glass R, Gentsch J, Banyai K, Parashar U, Patel M. Distribution of rotavirus specific strains and strain specific effectiveness of the rotavirus vaccine after its introduction: a systematic review and metaanalysis. Lancet. 2014;14:847-967.

12. Zeey NB, Kapanda L, Tate JE, Jere KC, Komara MI, Nakagomi O, Mwansambo C, Costello A, Parashar UD, Heyderman RS, French N, Cunliffe NA. Effectiveness of monovalent rotavirus vaccine in infants in Malawi after programmatic roll-out:an observational and case control study. Lancet. 2015;15:422-8.

13. Parashar UD, Burton A, Lanata C, Boschi-Pinto C, Shibuya K, Steele D, Birmingham M, Glass RI. Global mortality associated with rotavirus disease among children in 2004. J Infect Dis. 2009;200:S9-15.

14. Fischer TK, Valentiner-Branth $P$, Steinsland $H$, Perch $M$, Santos $G$, Aaby $\mathrm{P}, \mathrm{Mølbak} \mathrm{K}$, Sommerfelt H. Protective immunity after natural rotavirus 
infection: a community cohort study of newborn children in GuineaBissau, west Africa. J Infect Dis. 2002;186(5):593-7.

15. Moyo SJ, Blomberg B, Havenik K, Kommedal O, Vainio K, Maselle SY, et al. Genetic diversity of circulating rotavirus strains in Tanzania prior to the introduction of vaccination. PLoS ONE. 2014;9(5):e97562.

16. Ouermi $D$, et al. Prevalence of rotavirus, adenovirus and enteric parasites among pediatric patients attending Saint Camille Medical Centre in Ouagadougou. Pak J Biol Sci. 2007;10(23):4266-70.

17. Temu A, Kamugisha E, Mwizamholya DL, Hokororo A, Seni J, Mshana SE. Prevalence and factors associated with Group A rotavirus infection among children with acute diarrhoea in Mwanza. Tanzania. J Infect Dev Ctry. 2012;6(6):508-15.

18. Phan TG, Khamrin P, Quang TD, Dey SK, Takanashi S, Okitsu S, et al. Detection and genetic characteristics of Group A rotavirus strains circulating among children with acute gastroenteritis in Japan. J Virol. 2007;81(9):4645-53.

19. Badani AA, Areqi AL, Majily A, Sallami SA, Madhagi AL, Kamarany MAL, Rotavirus diarrhoea among children in Taiz, Yemen: prevalence-risk factors and detection of genotypes. Int J Pediatr. 2014;2014:1-9.

20. Nakawesi J, Wobudeya E, Ndeezi G, Mworozi E, Tumwine K. Prevalence and factors associated with rotavirus infection among children admitted with acute diarrhoea in Uganda. BMC Paediatr. 2010;10:69.
21. Gachanja E, Buza J, Petrucka P. Molecular detection of group a rotavirus in children under five in urban and peri-urban arusha. Tanzania. Br J Med Med Res. 2016;12(12):1-9.

22. Kiulia NM, Kamenwa R, Irimu G, Nyangao JO, Gatheru Z, Nyachieo A, Steele AD, Mwenda JM. The epidemiology of human rotavirus associated with diarrhoea in Kenyan children: a review. J Trop Pediatr. $2008 \mathrm{Jul}$ 1;54(6):401-5.

23. Ansari S, Sherchand JB, Rijal BP, Parajuli K, Mishra SK, Dahal RK, Shrestha S, Tandukar S, Chaudhary R, Kattel HP, Basnet A. Characterization of rotavirus causing acute diarrhoea in children in Kathmandu, Nepal, showing the dominance of serotype G12. J Med Microbiol. 2013;62(1):114-20.

24. Sánchez-Uribe E, Esparza-Aguilar M, Gastañaduy PA, Desai R, Patel M, Richardson V. Risk factors associated with rotavirus gastroenteritis during a community outbreak in Chiapas, Mexico during the postvaccination era. J Pediatr Infect Dis Soc. 2013;2(1):15-20.

25. Li Y, Wang SM, Zhen SS, Chen Y, Deng W, Kilgore PE, Wang XY. Diversity of rotavirus strains causing diarrhoea in 5 years old chinese children: a systematic review. PLoS ONE. 2014;9(1):e84699.

26. Moyo SJ, Gro N, Kirsti V, Matee MI, Kitundu J, Maselle SY, Langeland N, Myrmel H. Prevalence of enteropathogenic viruses and molecular characterization of group A rotavirus among children with diarrhea in Dar es Salaam Tanzania. BMC Public Health. 2007;7(1):359.

\section{Submit your next manuscript to BioMed Central and we will help you at every step:}

- We accept pre-submission inquiries

- Our selector tool helps you to find the most relevant journal

- We provide round the clock customer support

- Convenient online submission

- Thorough peer review

- Inclusion in PubMed and all major indexing services

- Maximum visibility for your research

Submit your manuscript at www.biomedcentral.com/submit
() Biomed Central 